\title{
O selo de Jade Imperial Taiping e o Reino do Filho Chinês de Deus
}

\author{
Victor Artuza*
}

DOI: 10.11606/issn.2318-8855.v8i8p13-44

Resumo: Em meio a um período conturbado (século XIX), os manchus, detentores do domínio sobre a Dinastia Qing enfrentaram grandes dificuldades, seja pelas relações estabelecidas com o exterior ou pelas agitações internas, causadas por inúmeras revoltas. No entanto, uma delas merece especial atenção, seja por sua magnitude ou pela reverberação tanto no exterior como também na história da China. Esta seria a Rebelião Taiping, que através de seu líder, Hong Xiuquan, toma forma e se expande juntamente com a fé cristã, estabelecida pelo mesmo. Tal rebelião assume impactante extensão, na união de um cristianismo próprio e a crença de seus fiéis seguidores para com o seu líder - o "Filho Chinês de Deus", que reivindicava o título de "Rei Celestial" - que constituíram o então "Reino Celestial Taiping". Deste modo, a descrição e o aprofundamento no estudo da Rebelião pode ser obtido através do chamado Selo de Jade Imperial Taiping (太平玉趛), trazido aqui como um objeto que em primeira instancia se traduz, para que seja passível da explicação analítica, suscitando assim um maior aprofundamento sobre as caracterizações e a compreensão do que foi esta rebelião.

Palavras-chaves: Dinastia Qing, Hong Xiuquan, Rebelião Taiping, Selo de Jade Imperial Taiping.

\footnotetext{
* Graduado em história pela Faculdade de Filosofia, Letras e Ciências Humanas da Universidade de São Paulo (USP), realizou um intercambio durante o período de graduação na Faculdade de Língua Estrangeira de Xi'An (西安外国语大学) na cidade de Xi'An(西安) - China. Atualmente realiza mestrado na área de Relações Internacionais na Universidade de Jinan (暨南大学)， na cidade de Cantão(广州) China. E-mail: victor_artuza@yahoo.com.br
} 


\section{traduções}

\section{O Selo de Jade Imperial Taiping e o Reino do Filho Chinês de Deus}

\section{Introdução}

A relação dialética, observada do ponto de vista cíclico da interação entre causa-consequência, da crise interna e externa presentes na China, é de essencial importância para a compreensão da situação em que se encontrava o país na primeira metade do século XIX. Sendo assim, a imposição por parte dos ingleses de tratados desvantajosos causavam certa indignação por grande parte dos chineses, do mesmo modo que a presença estrangeira ${ }^{1}$ era um fator de agravamento de tal repulsa. O crescimento da população e a saída de prata do país foram fatores que igualmente influenciaram a crise externa e um maior avanço por parte dos países estrangeiros sobre a China, seguindo a linha que Spence (SPENCE, 1996a, p. 175) define, foram norteadores deste período.

Do mesmo modo, contudo, que devem ser considerados no contexto das crises das relações exteriores da China, esses levantes devem também ser vistos como o ponto culminante de um padrão de protestos que começou com o Lótus Branco e continuou por crises menos dramáticas, mas mesmo assim significativas, tanto no Norte como no Sul da China. [...] (SPENCE,1996a, p.176)

Este seria outro importante elemento defendido pelo autor, uma vez que a Revolta do Lótus Branco pôde ser vista como um "gatilho" em que acabou por direcionar o país a um "desgaste do tecido social", representados por fatores como: a perca de produtividade do sal; a exploração de trabalhadores decorrentes de formações de sub-redes burocráticas; o aumento da violência e de dissidências para com o Estado, principalmente com cunhos religiosos, o que acarretava em um choque cada vez maior entre a dinastia Qing e setores sociais fundamentalistas. Ao mesmo tempo havia uma crescente formação de unidades paramilitares desenvolvidas por

\footnotetext{
${ }^{1}$ Esta presença constituiu-se como um fator essencial para que Hong Xiuquan (洪秀全), o líder da Rebelião Taiping (太平), pudesse entrar em contato com a religião cristã e então erigisse sobre ela a estrutura do movimento.
} 


\section{traduções}

Victor Artuza

mandarins; esferas públicas sendo cada vez mais utilizadas para interesses particulares e a corrupção crescente dentro de órgãos governamentais que contribuíam para a implosão de muitas revoltas, como ainda afirma Jonathan Spence (SPENCE,1996a, p.176).

Por consequência deste aumento da instabilidade e dos choques para com o aparelho estatal, várias revoltas acabaram eclodindo, também houve a formação das Tríades (ou Sociedades do Céu e da Terra), as quais tinham um forte caráter antimanchu. Portanto, esta época se caracteriza como um momento muito conturbado na história da China, um período de difícil manutenção do poder por parte do manchus em plena dinastia Qing, o que iria corroborar para a queda do que seria a última dinastia chinesa. Logo, Fairbank e Goldman resumiriam de forma muito concisa e apropriada esse período, o qual colaboraria para o surgimento e a duração, por cerca de 13 anos da Rebelião Taiping:

Após 1850 o regime Qing estava quase destruído por rebeliões generalizadas. A incapacidade do imperador para subjugar os bárbaros Britânicos em 1842, apesar da Guerra do Ópio travada somente em meia dúzia de lugares na costa, tendo abalado o prestigio imperial. Em 1846-1848, além disso, desastres e fome estavam difundidas entre a população expandida da China. Não era uma surpresa que uma grande revolta se iniciaria em 1850. (FAIRBANK; GOLDMAN, 2001, p. 206, tradução própria.) ${ }^{2}$

\section{Hong Xiuquan, o Filho Chinês de Deus}

A partir do contexto citado acima, compreende-se melhor as razões que

\footnotetext{
${ }^{2}$ No original: "After 1850 the Qing regime was almost overwhelmed by widespread rebellions. The emperor's inability to subdue the British barbarians in 1842, even though the Opium War was fought at only half a dozen places on the seacoast, had shaken imperial prestige. In 1846-1848, moreover, flood and famine were widespread among China's expanded population. It is not surprising that a great uprising finally commenced in 1850."
} 


\section{traduções}

\section{O Selo de Jade Imperial Taiping e o Reino do Filho Chinês de Deus}

proporcionaram que a Rebelião Taiping, figura central abordada pelo selo ${ }^{3}$, acontecesse e viesse a adquirir tamanha magnitude. Entretanto, o que se deve atentar é para a figura desempenhada por seu principal líder, Hong Xiuquan (洪秀全), o qual exerce papel central na rebelião, uma vez que o surgimento do movimento se dá em função deste, assim como sua representação no selo. Portanto, entender como sua vida vincula-se ao que foi esta rebelião é aqui fundamental para uma melhor compreensão de quem foram os Taiping e quais eram seus objetivos.

Hong, nascido em 1814, veio de uma pobre família de origem Hakka4, estabelecida em Guangdong, onde era professor de seu vilarejo ${ }^{5}$. Seu nome verdadeiro era Hong Huoxiu. Realizou o exame público ${ }^{6}$ - o qual possibilitava a quem passasse obter o mais baixo nível do ranking oficial de intelectual ${ }^{7}$ - por quatro vezes seguidas. Em 1836, em sua segunda tentativa neste exame, foi para a cidade de Guangzhou, onde entrou em contato com um missionário protestante e com um discípulo chinês deste. Eles o entregaram tratados escritos por Liang $\mathrm{Afa}^{8}$, que eram manuscritos, excertos, traduções de partes da Bíblia, em chinês, mas naquele momento, Hong ignorou-os, sem porém jogá-los fora, e sim conservando-os consigo.

No Festival Qingming ${ }^{9}$, Hong visitou o local onde ficava sua terra natal, e

\footnotetext{
${ }^{3}$ O Selo de Jade Imperial Taiping, o qual será analisado posteriormente.

${ }^{4}$ Hakka (客家, Kejia) é um grupo etnico chinês, de origem Han que havia migrado da região centronorte, do país, para a região sul.

${ }^{5}$ Considerado já entre os habitantes locais um cargo de grande importância.

${ }^{6}$ Também chamados de exames imperiais. Eram sistemas de exames, realizados pelas dinastias Ming e Qing, para que se pudesse ter acesso à uma carreira "pública", dentro de órgãos públicos, ou seja, do Estado.

${ }^{7}$ O que já era considerado um cargo de prestigio, pois uma vez dentro da estrutura estatal, com um cargo dentro do governo (um cargo público), além de trazer grande honra para sua família conseguiria ajudar com as despesas da casa e à sustentar sua família (que naquele período se referia principalmente à mãe, pai, avós, irmãos e irmãs).

${ }^{8}$ Liang Afa, um cristão chinês de Cantão, um dos primeiros missionários cristãos chineses.

${ }^{9}$ Festival em que se reverencia os mortos.
} 


\section{traduções}

Victor Artuza

quando estava voltando para casa, adoeceu em Guanlubu. O estado em que se encontrava era muito grave, fazendo com que Hong acreditasse que seria seu fim, chamando a todos da família, e os fazendo crer que assim seria ${ }^{10}$. Neste período, a doença o levou a ter sonhos. Nestes sonhos, Hong, estando no "Céu" ou "paraíso", prostrava-se na frente de um homem de barbas douradas, usando uma túnica preta de dragão, que o chamava de filho, este homem dizia-lhe que na terra os demônios estavam enganando as pessoas, disfarçando-se delas, e as pessoas faziam oferendas e os reverenciavam, deste modo propagando o caos e magoando "o Pai". Para ajudálo, Hong obedece a ordem deste de exterminar os demônios, expurgá-los da terra. Para esta tarefa, "seu pai" Ihe dá dois presentes, uma espada e um selo, e então Hong, com a ajuda de seu irmão mais velho, que carregava o selo, ia aniquilando os demônios. Nestes mesmos sonhos, Hong recebia de seu pai um novo nome, Hong XiuQuan, onde Quan (全), que significa "completo" ou “o todo", refletia assim toda a conjuntura do poder de Hong. Era mister que o nome fosse trocado, uma vez que seu antigo nome, Hong Huoxiu, era considerado um taboo, já que huo (火) fazia parte do nome de seu pai Yue-huo-hua. (SPENCE,1996b. p.65-68)

Ficou doente deste modo por volta de 40 dias, depois de melhorar um pouco, tinha períodos de alucinações - levantando-se, agitando-se muito e gritando furioso, como se lutasse com alguém - e períodos em que brigava com parentes principalmente com seu pai, dizendo não ser seu verdadeiro pai. Então, como seu “pai verdadeiro", Deus o Pai, Ihe deu um novo nome, começou a utilizá-lo, obrigando os familiares a também o utilizarem e não o chamassem mais pelo antigo nome, assim

\footnotetext{
${ }^{10}$ Pois assim que a doença começa a dar indícios, seu corpo fica fraco indo para cama e tendo sonhos, os quais eram relacionados com a crenças chinesas, principalmente no Budismo, e que em sua interpretação eram o anúncio do fim, ou seja de sua morte.
} 


\section{traduções}

\section{O Selo de Jade Imperial Taiping e o Reino do Filho Chinês de Deus}

descreve Spence (SPENCE,1996b, p. 68 e 69). A seguir, o autor ainda enuncia:

Por ora lentamente Hong Xiuquan se acalma. Sua família e amigos começam a utilizar seu novo nome, Sua esposa, Lai, carrega sua filha. Ele retorna a seus textos Confucianos, e assim logo inicia novamente os preparativos para os exames. Ele reassume seus deveres de ensino no vilarejo próximo. O sonho está além da interpretação, e portanto pelo senso comum não tem nenhum sentido. (SPENCE, 1996b, p.69, tradução própria.) ${ }^{11}$

Então, logo depois de retomar sua antiga vida, Li Jingfang ${ }^{12}$ pede emprestado os tratados em chinês, que estavam em posse de Hong. Após sua leitura, Li devolve-os à Hong e pede a ele que os leia, assim o fazendo (SPENCE, 1996b). Hong, portanto, analisa a situação em que se encontrava, juntando pouco a pouco, "todos os fatores" que rodeavam sua vida: a situação local e nacional, seja pelo maior avanço estrangeiro - como por exemplo a Guerra do Ópio, a qual em seu primeiro desfecho (1842) , impõe o tratado de Nanjing, transformando Guangzhou em um porto comercial -, ou pela crise interna - como por exemplo a corrupção dentro das estruturas estatais -; Os tratados de Liang Afa; E principalmente aos sonhos, que há um tempo atrás tinha tido, no qual podia-se identificar a presença de Jesus Cristo, "filho de Deus", e "Deus o Pai"13.

Mesmo assim, decide tentar pela quarta vez o exame público, fracassando uma última vez. Logo:

Comparado com a vez passada, Hong Xiuquan parecia um pouco mais calmo,

\footnotetext{
${ }^{11}$ No original: "Yet slowly Hong Xiuquan calms down. Family and Friends grow used to his new name, His wife, Lai, bears him a baby girl. He returns to his Confucian texts, and begins to prepare yet again for the examinations. He resumes his teaching duties at a nearby village. The dream is beyond interpretation, and therefore by common consent it can have no meaning."

${ }^{12}$ Um amigo e parente distante de Hong XiuQuan.

13 Para uma análise mais detalhada deste "fatores" que influenciaram o pensamento de Hong, a mudança de mentalidade com relação a realidade que o cercava, ver: SPENCE, Jonathan D. The Key. In: _. God's Chinese Son: The Taiping Heavenly Kingdom of Hong Xiuquan. New York: W.W. Norton \& Company, 1996b, p. 70-86.
} 


\section{traduções}

Victor Artuza

ele somente derrubou os clássicos confucianos de sua casa no chão ${ }^{14}$. Ao mesmo tempo, fez um juramento que, de agora em diante não mais participaria dos exames imperiais dos Qing: "Eu mesmo irei organizar os exames imperiais que escolherão, entre todos, os melhores intelectuais ${ }^{15}$." Estas eram palavras em um momento de acesso de raiva, que por falhar repetidas vezes no exame imperial, demonstrava conjuntamente o desespero e fúria de Hong Xiuquan. E talvez ele próprio nem tenha percebido que tais palavras de revolta, 10 anos depois, inesperadamente iriam se tornar realidade. (HISTÓRIA Geral da China (中国通史), 2016, 4min e25 s., tradução ${\text { própria. })^{16}}^{16}$

Neste momento, Hong percebe o quanto os manuscritos, em sua percepção, aproximavam-se da realidade que o cercava e que aqueles sonhos que tivera tempos atrás eram realmente “Deus o Pai” que tinha entrado em contato com o próprio Hong Xiuquan. Tal explicação é apresentada por Spence, neste seguinte, longo, porém muito completo, trecho:

A coleção de tratados é longa, cheia de estranhos termos e estranhos nomes, e existe muitas coisas que Liang $^{17}$ não explica. Mas Hong sente que a chave tinha aberto sua mente e seu coração. O homem com barbas douradas com quem ele sonhara, e para quem ele lutou com os demônios, é Deus o Pai, o Senhor Ye-huo-hua, quem criou o Céu e a Terra. O irmão mais velho que fazia cintilar o selo dourado sobre os demônios, lutando ao lado de Hong, mas que o repreendeu severamente é Jesus o Salvador, filho de Deus, morto na cruz e que retornou novamente para o Céu. Os retentores que receberam Hong e o ajudaram em suas batalhas celestiais eram os anjos que viviam com Deus. Os textos desenrolados diante de seus olhos ou explicados à ele ponto à ponto são as palavras de Liang, ou as palavras de outros textos sagrados transcritos ou resumidos por Liang. O único mal, Yan Luo, é o diabo serpente demoníaca

\footnotetext{
${ }^{14}$ A simbologia por traz deste ocorrido, apesar de sutil nos revela muito. Um total "abandono" de uma tradição chinesa que se fundamenta no estudos dos clássicos chineses, a uma renúncia e afastamento dos ideias pregados tanto pelo governo, como por uma tradição cultural chinesa, representando assim uma ruptura entre Hong para com sua crença e conservadorismo advindo da tradição chinesa.

${ }^{15}$ Isto significava que ele queria se tornar imperador, pois somente o imperador tinha o poder de mudar os exames imperais e por consequência, indiretamente, escolher os intelectuais que fariam parte de seu governo.

${ }^{16}$ No original: “相比上一次洪秀全显得略为平静, 他只是把家里的经书都丢在了地上。同时发誓从此以后再也 不参加清朝科举. 上等我自己来开科去天下士罢”这是洪秀全在屡次落第的绝望和愤怒中所说的一句气话。或 许他自己也没有想到这句气话在十几年后竟然变成了现实".

${ }^{17}$ Liang Afa.
} 


\section{traduções}

\section{O Selo de Jade Imperial Taiping e o Reino do Filho Chinês de Deus}

que arruinou a vida feliz do homem e da mulher em seus primeiro idílico jardim. A espada a qual Hong lutou contra os demônios era a espada que guardava o portão leste do Paraíso. Deus fala diretamente com a humanidade, como ele fez com Moises no Monte Sinai, e como ele fez com Hong. Jesus viveu e caminhou sobre a Terra. A que quase dizimou todas as coisas vivas é um sinal do próprio destino de Hong. Seu nome Huo, de fogo, era taboo pelo fato de ser o nome do meio de Deus o Pai. Seu novo nome Quan - "completo" ou "todo" - começa, termina, e reverbera sobre os textos sagrados. Os exames confucianos são vaidades inúteis, espalhando falsas esperanças, gerando falsos procedimentos. Os estrangeiros, a despeito do ópio e da ira de alguns deles, tem boas intenções e irão salvar a terra da morte. Ídolos são malignos, e os dias de festa que marcam o início do ano chinês não reflete os ritmos da adoração ao alto Deus. O pecado destrói o mundo, incentivado por falsos padres, os lúbricos, os pornógrafos. Os rituais de limpeza os quais Hong participou quando passou pelo Céu eram previsões de seu batismo. Existem, ainda, legiões de demônios para exterminar na Terra, pois o mal se infiltrou em toda a raça humana. E desde que Jesus é Filho de Deus, e também irmão mais velho de Hong, então Hong é literalmente o Filho Chinês de Deus. (SPENCE, 1996b, p.88-89, tradução própria) ${ }^{18}$

Este trecho compila muitas valiosas informações, as quais analisadas por

\footnotetext{
${ }^{18}$ No original: "The collection of tracts is long, full of strange terms and stranger names, and there are many things that Liang does not explain. But Hong feels the key has opened up his head and heart. The man with the golden beard of whom he dreamed, and for whom he fought the demons, is God the Father, the Lord Ye-huo-hua, who created Heaven and earth. The elder brother who shone the golden seal upon the demons, fought at Hong's side, yet scolded him severely is Jesus the Savior, son of God, killed on the cross and returned again to Heaven. The retainers who welcomed Hong and helped him in his heavenly battles are the angels who live with God. The texts unrolled before his eyes or explained to him point by point are the words of Liangs, or the words of other sacred texts that Liang transcribed or summarized. The evil one, Yan Luo, is the demon devil serpent who ruined the happy life of man and woman in their first idyllic garden. The sword with which Hong fought the demons is like the sword that guarded the eastern gate of Paradise. God does speak directly to mankind, as he did to Moses on Mount Sinai, and as he has to Hong. Jesus too has lived and toiled upon the earth. The raging flood that almost swept away all living things is a sign of Hong's own destiny. His name Huo, of fire, was tabooed because it was the middle name of God the Father. His new name Quan - "complete" or "whole" - begins, closes, and reverberates throughout the sacred texts. The Confucian examinations are worthless vanities, spreading false hopes, engendering false procedures. The foreigners, despite the opium and the wrath of some of their number, have good intentions, and perhaps will save the land from death. Idols are evil, and the festival days that mark the working Chinese year do not reflect the rhythms of worship due the highest God. Sin ravages the world, encouraged by false priests, the lustful, the pornographers. The cleansing rituals that Hong went through in Heaven were foretellers of his baptism. There are legions of demons still to slay on earth, for evil has infiltrated all the human race. And since Jesus is the son of God, and also Hong's elder brother, then Hong is literally God's Chinese son".
} 


\section{traduções}

Victor Artuza

Spence explicitam o contexto como também contribuem para o entendimento da relação entre Hong e a teologia cristã (a qual este teve acesso). Primeiramente, a partir do trecho é possível observar como todo o contexto e as explicações dos tratados de Liang Afa caracterizaram para Hong a veracidade de seus sonhos, uma vez que o conteúdo dos manuscritos continham partes em que Deus diretamente se comunica com as pessoas, realçava assim a veracidade dos sonhos - pois como Deus já havia se comunicado com outros (como citado no trecho: Moises), por que não poderia ter se comunicado com Hong, através de seus sonhos, conferindo-lhe seu verdadeiro nome, seu verdadeiro eu? - que o próprio "Filho Chinês de Deus", ou como futuramente se chamaria, "Deus Celestial" tivera.

Em segundo lugar, na descrição do autor, Hong, ao descrever Deus e conjuntamente toda a mitologia cristã, funde-os à mitologia chinesa (ou contrariamente, funde a mitologia chinesa à cristã). Uma vez que compara e de certa forma recoloca cada entidade cristã em um posto semelhante para com as entidades chinesas - como por exemplo o Diabo, substituindo-o pelo Yan Luo (阎罗), mantendo o nome chinês, mas as principais características advindas do cristianismo (mesmo que seja difícil definir por inteiro as características que esta concepção de “Diabo” carrega).

Um terceiro aspecto retirado do trecho é com relação até onde os manuscritos continham as palavras diretas dos textos sagrados, ou se elas eram interpretações do próprio Liang Afa, não havendo como discerni-las somente a partir da leitura destes tratados, acarretando divergências para com a teologia cristã pregada pelo ocidente. Um quarto aspecto abordado seria o relacionamento com os estrangeiros, uma vez mal vista entre os chineses, no entanto diante de tais "provas" que agora Hong possuía, eles (para Hong): "tem boas intenções, e talvez irão salvar a terra da morte." 


\section{traduções}

\section{O Selo de Jade Imperial Taiping e o Reino do Filho Chinês de Deus}

(SPENCE, 1996b, p.88-89, tradução nossa) ${ }^{19}$, já que conjuntamente os preceitos cristãos advinham dos mesmos. O quinto ponto, que pode ser extraído da análise do autor, é o objetivo que Hong teria de eliminar os incontáveis demônios presentes na Terra. Este fator seria essencial, pois iria influenciar a caracterização da dinastia Qing (e dos manchus), sendo esta a representação de tais demônios e que Hong, e mais futuramente os Taiping, teriam o objetivo de aniquila-los.

\section{"Sociedade dos Veneradores de Deus"}

Destarte Hong, agora "Filho Chinês de Deus", começa a pregar, formando a chamada "Sociedade dos Veneradores de Deus", erigindo assim em pouco tempo um grande número de seguidores, os quais seguiam-no devido as suas fortes convicções religiosas. O movimento então cresceu rapidamente e ganhou atenção de outras partes interessadas no enfraquecimento e no extermínio dos Qing.

Entre tais grupos estavam: As Tríades, que se opunham aos manchus; os estrangeiros que inicialmente enxergavam este movimento, de bases cristãs, como algo positivo - seja pelo fato da expansão da fé cristã ou da possibilidade de "tirar de campo" os Qing, os quais dificultavam a compra de produtos estrangeiros (como por exemplo o ópio).

Outro grupo importante eram os Hakka, ou Kejia(客家), (grupo étnico a qual Hong pertencia) por serem um povo considerado "estrangeiro", ou seja, detinham uma posição de estranhamento para com os outros povos da região - principalmente no sul, já que haviam imigrado do norte e mantinham suas tradições e costumes considerados estranhos aos povos daquela região ${ }^{20}$-. Neste período, os Hakka

\footnotetext{
${ }^{19}$ No original: [...] have good intentions, and perhaps will save the land from death. [...]

${ }^{20}$ Importante salientar aqui que existem grandes diferenças culturais entre o Norte e o Sul na China, uma vez que seus grupos étnicos e as culturas e costumes que carregam são muito divergentes entre si.
} 


\section{traduções}

Victor Artuza

passavam por condições péssimas de vida e que por fim, muito possível por este motivo, seguiram, em sua grande maioria, os passos de Hong.

Já em 1847 Hong e seus seguidores foram para a região chamada de montanha dos Cardos, onde se juntaram a um amigo de Hong, que havia participado da criação da "Sociedade dos Veneradores de Deus". Juntos, então, foram adquirindo adeptos entre as tribos montanhesas do Yaos e Zhuangs, constituindo a base da formação que daria força à Rebelião (por agruparem mineradores, prestamistas, entre outros com funções importantes para a formação do futuro governo Taiping). Assim Gernet aponta:

[...]A rapidez com que o movimento que iria dar origem aos Taiping alastrou na província do Guangxi e alcançou as províncias do Guangdong, do Médio e do Baizo-Yangzi explica-se, ao mesmo tempo que pela miséria e pela injustiça, pelo trabalho subterrâneo aí realizado pelas organizações clandestinas filiadas na Sociedade da Tríade (Sanhehui), também conhecida pelo nome de Sociedade do Céu e da Terra (Tiandihui). (GERNET, 1974, p. 90.)

Rapidamente a "Sociedade dos Veneradores de Deus" se expande, adquirindo um grande contingente de seguidores. Entre eles "The chief military leader was an illiterate charcoal burner named Yang ${ }^{21}$, who had the wit to receive God's visitations and speak with His voice in a way that left Hong sincerely speechless." (FAIRBANK; GOLDMAN.2001, p.208); e o jovem Shi Dakai (石达开), filho de terratenentes e um general astuto. Estes seguidores iriam se tornar líderes importantes para a rebelião, os quais viriam a desempenhar papeis fundamentais com a implementação de táticas e estratégias militares. Juntando isto às alianças que aos poucos vão se estabelecendo, esta sociedade começa a determinar seus territórios sob sua influência.

No ano de 1850, com por volta de 20 mil seguidores, a "Sociedade dos

\footnotetext{
${ }^{21}$ Yang Xiuqing(杨秀清)
} 


\title{
traduções
}

\section{O Selo de Jade Imperial Taiping e o Reino do Filho Chinês de Deus}

Veneradores de Deus" começou a instituir bases burocráticas, financeiras, e militares, as quais ofereciam autonomia à rebelião, que vinha se estruturando. Assim, no final deste mesmo ano houve uma tentativa governamental de atacar o território sobre o domínio da sociedade liderada pelo "Filho Chinês de Deus", tendo o objetivo de recuperar a região, sem obter sucesso no entanto. Em outubro de 1850 Hong funda o Reino Celestial Taiping (太平天国 - Taiping Tianguo) ${ }^{22}$, auto declarando-se Rei Celestial deste novo reino.

\section{Reino Celestial Taiping}

Muitas regras foram impostas sobre o novo reino, demonstrando que pouco a pouco a rebelião se radicalizava. Entre os regulamentos estavam a imposição: da segregação obrigatória entre os sexos - em que mulheres podiam se alistar no exército (havia um grande e forte exército formado por estas mulheres Taipings); da absoluta proibição do consumo de ópio, álcool e da prostituição. Deste modo, o movimento era extremamente puritano, devendo-se seguir toda a teologia Taiping à risca, quem desobedecesse as regras seria punido pública e severamente. ${ }^{23}$

\begin{abstract}
Ambos nacionalistas e comunistas tentaram resgatar do movimento Taiping algum protótipo positivo da reforma social e do nacionalismo anti manchu. Os Taipings eram contrários a todos os males usuais - aposta, ópio, tabaco, idolatria, adultério, prostituição, enfaixar os pés; e eles davam especial atenção à mulheres, que mantinham e muitas vezes serviam nos exércitos e corriam nos palácios no lugar dos eunucos. [...] (FAIRBANK; GOLDMAN.NET, 2001, p. 210-211, tradução própria.) ${ }^{24}$
\end{abstract}

\footnotetext{
${ }^{22}$ Taiping(太平)significa grande paz, optou-se por manter o termo original, por ser mais habitualmente usado.

${ }^{23}$ Em seu incrível trabalho Spence relata sobre várias punições, a maioria públicas, cada uma divergindo de acordo com a regra/lei que havia sido infringida. SPENCE, Jonathan D. God's Chinese Son: The Taiping Heavenly Kingdom of Hong Xiuquan. New York: W.W. Norton \& Company, 1996b.

${ }^{24}$ No original: "Both Nationalists and Communists of a later day have tried to salvage from the Taiping movement some positive prototype of anti-Manchu nationalism and social reform. The Taipings were against all the usual evils - gambling, opium, tobacco, idolatry, adultery, prostitution, footbinding;
} 


\section{traduções}

Victor Artuza

Foi criado também um tesouro público, já que tudo era partilhado, à ninguém era permitido ter luxo, e o dinheiro era dividido entre todos de "forma igualitária". E agora os Taiping deveriam parar de fazer tranças e começar a deixar o cabelo crescer, isto fazia com que eles chamassem mais atenção, sendo chamados de "rebeldes cabeludos". Este caráter significava uma rebeldia à dinastia Qing, já que todos eram obrigados à ter tranças, um estilo de cabelo advindo da cultura manchu. ${ }^{25}$

A cristandade Taiping que foi se formando, em parte emprestada do próprio cristianismo, em parte reinventada a modo que se enquadrasse na sociedade chinesa e, em certas medidas, nas vontades de Hong, foram constituindo as bases religiosas da rebelião (FAIRBANK; GOLDMAN, 2001, p.208).

Cristianismo Taiping metade emprestado e metade recriado para os propósitos chineses um cheio repertório de preces, hinos, e rituais, e pregados pela fraternidade e irmandade de toda a humanidade sob a paternidade de um verdadeiro e único Deus. Ao contrário de uma política pacifista do Taoismo e o sobrenatural do Budismo, o Velho Testamento Protestante oferecia um chamado ao triunfo para o povo militante em marcha contra seus opressores. Os cadáveres originais dos reais fieis Hakka que estavam em valente batalha e mais atenciosos em frente ao povo comum. E não é de admirar! Os ensinamentos de Hong criaram uma nova seita Chinesa organizada para a Guerra. Utilizou verdadeiras técnicas desenvolvidas durante os 1800 anos da história de cristianismo para inculcar uma fé ardente em cada indivíduo e assegurar seu ou sua performance em seus serviços. Cristianismo Taiping era um exclusivo amálgama de ideias e práticas ocidente-oriente equipadas para a ação militar, algo semelhante que não foi visto até a China emprestar e ressignificar o Marxismo-Leninismo um século depois. (FAIRBANK; GOLDMAN,

and they gave special scope to women, who supported and sometimes served in the army and ran the palaces in place of eunuchs.[...]"

${ }^{25}$ As famosas tranças da dinastia Qing eram o estilo de cabelo utilizado pelos chineses, no tempo em que os manchus reinavam, uma vez que esse era um costume destes. Este estilo de cabelo se caracterizava pelos homens rasparem a frente da cabeça e deixarem uma trança ou "rabicho" (um termo tanto pejorativo utilizado pelos brasileiros durante o séc. XIX), sendo que a trança se diferenciou durante o tempo em que os Qings reinaram. Chamadas de "rabo de vaca", "rabo de porco" e "rabo de rato", eles representam a grossura da trança, do mais grosso ao mais fino, do mais antigo ao mais recente, respectivamente. 


\section{traduções}

\section{O Selo de Jade Imperial Taiping e o Reino do Filho Chinês de Deus}

2001, p.208, tradução própria.) $)^{26}$

Desta forma, o cristianismo Taiping se demonstrava como um amalgama de ideias e conceitos orientais e ocidentais, um certo sincretismo religioso como já citado, pois inclui muitas divindades chinesas com divindades cristãs, um novo e totalmente diferente tipo de cristianismo. Este fato é de extrema importância para se entender como Hong se auto afirmava, como os Taiping se auto afirmavam, e como se erigiam as estruturas do Reino Celestial, e que serão representadas no selo.

Não se sabe ao certo quando um confronto aberto com os Qing surgiu, porém, foi em 1850 que os confrontos se intensificaram, e como consequência, no ano seguinte esta situação já não seria mais a mesma. Neste sentido, os Qing começam a investir contra agora o recém formado "Reino Celestial Taiping". Estes embates eclodiram na fronteira entre Guanxi e Guandong até 1851. Data em que os Taiping tomam a cidade de Yongan, juntamente com um grande abastecimento tanto de dinheiro, como de comida e novos "adeptos". Tal significativa conquista, na visão de Spence, seria a primeira grande conquista dos Taiping, a conquista de uma cidade a qual serviria como o primeiro posto Taiping ${ }^{27}$. Já no ano seguinte, os Taiping tentam avançar sobre Guilin, capital de Guangxi, como também Changsha, porém, ambos os casos resultaram em fracassos.

\footnotetext{
${ }^{26}$ No original: "Taiping Christianity half-borrowed and half-recreated for Chinese purposes a full repertoire of prayers, hymns, and rituals, and preached the brotherhood and sisterhood of all mankind under the fatherhood of the one true and only God. Unlike the political passivity of Daoism and the otherworldliness of Buddhism, the Protestant Old Testament offered trumpet calls to a militant people on the march against their oppressors. The original corps of Hakka true believers were the bravest in battle and the most considerate toward the common people. And no wonder! Hong's teaching created a new Chinese sect organized for war. It used tried and true techniques evolved during 1,800 years of Christian history to inculcate an ardent faith in each individual and ensure his or her performance in its service. Taiping Christianity was a unique East-West amalgam of ideas and practices geared to militant action, the like of which was not seen again until China borrowed and sinified Marxism-Leninism a century later".

${ }^{27}$ Talvez aqui é que o conflito entre Taiping e Qing tenha se tornado aberto.
} 


\section{traduções}

Victor Artuza

“[...] Nesse ponto, as proclamações taipings tornaram-se mais belicosas, numa tentativa de recrutar novos contingentes [...]" (SPENCE,1996, p. 182.) Sejam por causa das forças exercidas pelos grupos aliados, com a intenção de atacar diretamente os governantes manchus, ou pela expansão da fé cristã. Criando a crença cada vez maior em que os manchus representariam os demônios, deixando a humanidade entregue ao pecado, e os Taiping seriam detentores da indispensável missão de expurgar este mal.

No mês de dezembro do ano de 1852 adentraram Yuezhou, que fica em Dongting, contudo, esta, diferentemente das outras, era uma cidade rica e antiga, o que implicava na aquisição de grandes quantidades de suprimentos e de dinheiro. Depois deste ocorrido, houveram sucessivos êxitos, e em 1853, os Taiping avançaram sobre a cidade de Nanjing.

\section{Capital Celestial}

O avanço sobre Nanjing fora uma grande conquista, já que naquela época esta era a capital da mais rica província do sul da China, centro da intelectualidade, ou seja, uma cidade não somente rica, porém importante política e economicamente. Em sua invasão, todos os manchus foram mortos, mesmo aqueles que não o foram em batalha, foram queimados, esfaqueados ou afogados. O fim da invasão se deu com o estabelecimento de Hong no antigo palácio cede da dinastia Ming, localizado dentro da cidade. Foi nesta grande cidade que o Reino Celestial Taiping fixou sua capital, nomeada pelos revoltosos de Tianjing (天景), Capital Celeste ou Capital Celestial, que durou 11 anos, de 1853 a 1864, sob o reinado do "Rei Celestial", Hong Xiuquang 


\section{traduções}

\section{O Selo de Jade Imperial Taiping e o Reino do Filho Chinês de Deus}

A partir disso, o exames imperiais dentro do Reino Celestial foram restituídos por Hong, diferenciavam-se somente por serem baseados na teologia cristã. Contudo, sua similaridade com os exames realizados pelos Qing era gigantesca, permitindo que as pessoas pudessem adentrar setores dentro da estrutura governamental. No entanto, a principal diferença era com relação à possibilidade de ascensão de mulheres a cargos dentro da burocracia.

Mesmo após o estabelecimento da Capital Celeste, continuou-se o esforço de se expandir o império numa tentativa de gradualmente aumentar o domínio Taiping. Despachando-se tropas em maio de 1853, com o objetivo de atacar Beijing, numa tentativa de destruir assim o "Covil dos Demônios", nome dado para a cidade pela presença dos manchus, a pretensão deste avanço era o de "expurgar o mal da terra" (SPENCE, 1996b). Em seguida, foram também planejadas várias investidas das tropas Taiping sobre Shanghai, o que deixava tanto os manchus, quanto os estrangeiros apreensivos, pois além de ser um porto muito importante, era também, após a Guerra do Ópio, um entreposto de domínio estrangeiro, o que também tornava-o um potente alvo de ataque para outros grupos rebeldes.

Assim, por volta de 1860-1861, o Selo de Jade Imperial Taiping deve ter sido criado, como Spence enuncia em seu principal trabalho sobre a Rebelião Taiping (SPENCE, 1996b). O selo era normalmente, utilizado nos documentos oficiais do Reino Celestial Taiping - que representavam Hong Xiuquan, quando não advindos diretamente do próprio - e poderiam ser decretos, cartas, correspondências, entre outros. Deste modo, a presença do selo em qualquer documento, além de "atestar" sua veracidade, oficializar suas intenções (que dependeriam do documento em questão), carregava um valor considerável muito grande pela questão do poder que representava. 


\section{traduções}

Victor Artuza

\section{Derroca do Reino Celestial Taiping}

No entanto, mesmo estabelecendo um reino poderoso, o qual teria o poder de destituir o comando dos Qing, não conseguiram fazer frente à Dinastia Qing e foram brutalmente derrotados. Isto deveu-se a vários fatores que juntos contribuíram para a derrocada da Rebelião Taiping, para que aos poucos o poder Taiping fosse se desintegrando, deixando-os "enfraquecidos", e assim os Qing pudessem pôr um fim a tal "potente inimigo".

Primeiramente a desintegração do poder, aconteceu pelo fato de muitos líderes, os chamados reis, morrerem em ofensivas, dois nas campanhas de 1852, como também pelo afastamento entre os líderes, como Yang Xiuqing, o qual foi morto por ordens do "Rei Celestial", após ter convencido os Taiping de que era a própria encarnação do Espírito Santo, o qual fazia com que Hong perdesse autoridade, já que suas ordens eram superadas pelas de Yang. E Shi Dakai, que em desacordo com o Rei Celestial, após o assassinato do Rei do Leste, foge e tenta estabelecer um reino independente em Sichuan, mas é morto por tropas manchus em 1863.

Com isso, Hong aos poucos ia perdendo prestígio, principalmente em Nanjing, para onde se mudou, deixando de lado seu avanço contra os manchus e destruindo sua reputação de líder religioso sério (SPENCE, 1996a, p. 184). Hong teria abandonado sua missão de destruir os demônios e então ficara isolado em seu palácio, no qual muitas pessoas não o viam, até mesmo seu próprio filho, Guifu. Em seu isolamento, ele passava a maior parte do tempo revisando os textos bíblicos, colocando-se em alguns trechos das escrituras sagradas, auto afirmando-se como Rei Celestial e centralizando seu papel dentro da teologia cristã, entre os Taiping. 


\section{traduções}

\section{O Selo de Jade Imperial Taiping e o Reino do Filho Chinês de Deus}

Em segundo lugar, os Taiping foram aos poucos perdendo apoio de grupos aliados, principalmente por causa de seus radicalismos. Para com as Tríades seria em detrimento do ascetismo e puritanismo dos "rebeldes de cabelo longo", que por sua vez, dificultava o comércio de ópio, já que seu consumo era vedado. Isto os afastava dos Taiping porque o comércio de ópio era a principal "atividade econômica" das Tríades.

Já os estrangeiros, devido principalmente ao estabelecimento da Capital Celeste, para onde missionários cristãos foram enviados, começam a formular uma posição diferente do que inicialmente tinham para com o movimento, porque os missionários cristãos enviados ao Reino Celestial visualizaram o fervor religioso dos Taiping com certa repulsa, pois a religião cristã (pregada pelo ocidente) tinha sido deturpada, e neste sentido, os revoltosos blasfemavam as doutrinas cristãs. A questão da proibição do ópio também afetava os comerciantes estrangeiros. E após os avanços dos Taiping sobre Shanghai, os estrangeiros, com medo de perderem este importante entreposto, apoiaram a dinastia Qing contra os rebeldes.

Em terceiro, os Taiping eram mal vistos pelos povos locais. Necessariamente com relação aos Hakkas (principal etnia participante do movimento), que eram vistos como tão estranhos quanto os estrangeiros pelos outros povos da região. Outra questão seriam as normas impostas pelo movimento, principalmente as que impunham a segregação entre os sexos, cujas quais não eram bem aceitas pela maior parte dos habitantes sob o domínio Taiping.

Um quarto fator da derrocada do Reino Celestial seria com relação às mudanças ocorridas dentro do governo dos Qing. O governante manchu que reinou, durante o maior tempo de vigência da Rebelião Taiping, era Xiangfeng (咸丰), de 1851 


\section{traduções}

Victor Artuza

até 1861, quando foi “deposto" por um golpe por Cixi (慈禧), esta, quando assume o poder em 1861, traz mudanças importantes ao império. Uma delas estaria ligada à encarregar Zeng Guofan (曾国藩) como líder das tropas Qing contra os Taipings.

Zeng Guofan era um intelectual chinês e confuciano fervoroso, que estabeleceu mudanças nos regimentos imperiais. Instituiu comandantes com caráter similar ao dele, os quais eram de confiança, prontamente estes mesmos comandantes escolhiam os integrantes de suas tropas, "selecionados a dedo", listando-os homem à homem, o que possibilitou criar-se uma rede de confiança e formar tropas mais fortes e unidas. (FAIRBANK; GOLDMAN. China, 2001, p.212.) Neste sentido, a estrutura formativa das tropas Qing se modifica, significando assim uma transformação dos enfrentamentos entre ambos os lados, o que foi refletido a partir de 1854, quando Zeng retoma Wuhang, e em 1858, Zhejiang, estes indicam pequenos e pontuais avanços, demonstrando agora a eficácia das tropas Qing. Contudo, o avanço dos Qing sobre os Taiping só começa a ser sistemático após 1860, (GERNE, 1974, p.93) o que resultaria no cerco à "Capital Celeste" em 1864.

Portanto, os Taiping vão perdendo territórios, e os avanços Qing cada vez mais os deixavam acuados, até que em 1864, Hong Xiuquan morre em seu palácio ${ }^{28}$. Neste mesmo ano, as três tropas comandadas por Zeng cercam Nanjing e mesmo assim os rebeldes, agora sem seu Rei Celestial, ainda tentam resistir aos "demônios invasores", mas os revoltosos não obtém sucesso. Portanto, chegava ao fim o Reino Celestial em julho de 1864, quando as tropas de Zeng adentram Nanjing e rapidamente dominam-na. Para a surpresa das tropas Qing, não houve nenhum rendimento por parte dos Taiping, pois eles optaram por se suicidar à render-se aos

\footnotetext{
${ }^{28}$ Este fato é um tanto obscuro, não sabendo-se exatamente quais foram as causas da morte de Hong.
} 


\title{
traduções
}

\section{O Selo de Jade Imperial Taiping e o Reino do Filho Chinês de Deus}

então "demônios manchus". Sendo assim, aqueles que não morreram na defesa da cidade, "facultativamente" "se juntavam e se queimavam" em grandes fogueiras dentro da própria cidade (SPENCE,1996a, p. 187). E assim:

\begin{abstract}
O Reino Celestial Taiping seguiria o mesmo caminho que Cartago - somente o nome sobreviveu. Os registros são tendenciosos por causa que os imperialistas destruíram a maioria dos escritos Taiping, exceto por alguns preservados sobretudo por estrangeiros (alguns foram achados somente neste século nas bibliotecas francesas e britânicas). Líderes de habilidade surgiram nos últimos anos, mas era tarde. A causa para a qual muitos tinham dado suas vidas deveriam ter tido muito à oferecer, mas somente em comparação com a já esgotada e velha ordem dos Manchus. (FAIRBANK; GOLDMAN, 2001, p.213, 214, tradução própria.) ${ }^{29}$
\end{abstract}

Muitos dos registros ou documentos Taiping foram destruídos, mas alguns sobreviveram. E a partir daí, estudos podem ser realizados numa tentativa de cada vez mais entender o que foi a Rebelião Taiping. Um dos artefatos que sobreviveram foi o Selo de Jade Imperial Taiping, este é essencial para o entendimento da rebelião, uma vez que contem traços do longo percurso transcorrido por esta rebelião. Muito do que foi explicitado acima, ao mesmo tempo que pode servir como base para o entendimento do selo, pode também ser melhor explicado pelo mesmo, já que o selo reúne diversificadas informações, as quais são essenciais dentro do discurso e da teologia apresentada pelos Taiping.

\footnotetext{
${ }^{29}$ No original: "The Taiping Heavenly Kingdom went the way of Carthage - only the name survived. The record is biased because the imperialists destroyed most Taiping writings, except for those preserved mainly by foreigners (some were found only in this century in French and British libraries). Leaders of ability emerged in the final years, but too late. A cause for which so many gave their lives must have had much to offer, but only in comparison with the effete old order under the Manchus".
} 


\section{traduções}

Victor Artuza

\section{Selo de Jade Imperial Taiping}

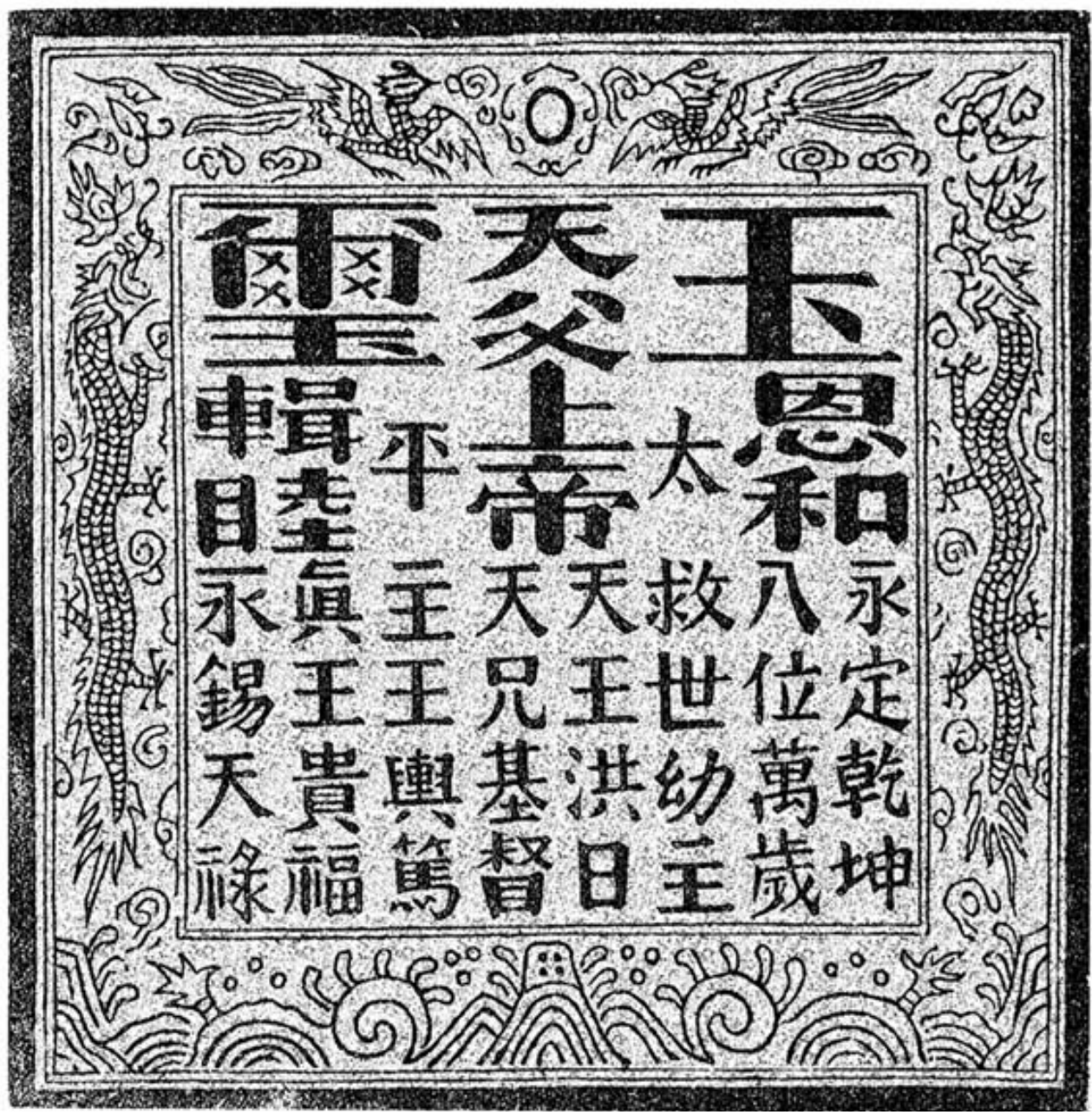

Imagem 1 - Impressão do Selo de Jade Imperial de Hong Xiuquan (太平玉疍/ Taiping Yuxi). Fonte: (LUO (罗), Suizu (隨祖), 1981).

Em prol de explicar de forma um tanto detalhada o Selo de Jade Imperial Taiping, preocupar-se-á inicialmente em expor as características do selo, depois apresentar-se-á a tradução de seu conteúdo, para que então assim possa-se analisálo. No entanto se faz mister explanar sobre a escolha de como se traduziu o nome do selo, traduzindo de 太平玉玺 para Selo de Jade Imperial Taiping, tendo assim, como objetivo traduzir para um nome que tivesse uma boa sonoridade e que ao mesmo 


\section{traduções}

\section{O Selo de Jade Imperial Taiping e o Reino do Filho Chinês de Deus}

tempo carregasse o sentido que este contém. Outro fator a se mencionar é que, como nas dinastias chinesas era comum o uso de selos de jade - os quais carregam esse sentido de serem imperiais, pelo fato de serem sempre relativos à alguma dinastia e não um selo de jade "comum" - e pela presença do nome da rebelião no selo, foi mantido o nome Taiping.

Portanto, para entender este documento, é indispensável saber que este selo era usado, como já dito antes, em muitos dos documentos "oficiais" do Reino Celestial Taiping, principalmente aqueles que levavam o nome do "Rei Celestial". Igualmente tinha a função de dar validade, demonstrando a veracidade do documento, outro motivo (interpretativo) seria o de demonstrar o poder que o selo carregava, como também ser um veículo que propagava a figura de Hong e da fé cristã Taiping pregada por ele.

Outro aspecto importante à analisar são as características do selo, como o tamanho, já que mede aproximadamente 20 centímetros de comprimento, 20 centímetros de largura e 10,1 centímetros de altura, juntamente como as figuras no entorno - há um mar, com fortes ondas na parte inferior; na lateral, dois dragões; mais acima destes, a representação de nuvens; por fim, na parte superior, duas fênix de adorno, e no centro destas, o Sol, as quais as fênix estão expostas (LUO (罗), Suizu ( 隨祖). 1981, p.30). Todos, dragões e fênix, estão olhando em direção ao Sol - o Sol aqui pode representar muitas coisas: pode representar as bênçãos de Deus sobre a rebelião; outra característica seria atribuída ao próprio Hong, já que em vida ele se dava o título: “洪日” (Hongri) uma vez que 日 (ri) pode carregar o sentido de sol; consequentemente, tudo que é representado no selo estar em direção ao Sol representaria o respeito e fé ao seu líder; igualmente pode-se entender esta simbologia como sendo que o Reino Celestial Taiping já fazia parte do "Reino dos 


\section{traduções}

Victor Artuza

Céus". Outro fator seria concernente à questão que os dragões e as fênix representariam à sociedade chinesa, e como estes estão inclinados em direção ao Sol, sua salvação poderia ser concretizada.

O fato de o selo ser formado de Jade ${ }^{30}$, toda a simbologia trazida em seus adornos, e igualmente por ser um selo imperial, representariam a importância do selo, do poder que este carregava, não somente perante os Taiping, como também perante os Qing, uma vez que somente o imperador poderia ter um selo, ainda mais um selo de Jade, desta forma, Hong desafiava o império manchu e o próprio imperador da China. Neste sentido, tais informações indicariam uma estruturação do modelo de cristandade propagado pelos Taiping, como estes sendo libertadores, que salvarão o mundo, e mesmo os chineses poderiam ser "libertos" das garras dos demônios manchus.

Concernente ao conteúdo mais evidente do selo, em sua escrita, fundamentalmente existem três formas de se ler o Selo de Jade Imperial Taiping, cada uma baseada em um aspecto importante, seja perante a leitura de um selo, seja para com as convicções que a rebelião trazia e suas características.

Primeiramente, de acordo com a base fundamental da escrita (LUO (罗), Suizu ( 随祖). 1981, p.30), seguindo uma tradição milenar da escrita clássica chinesa, da famosa caligrafia chinesa (书法), onde a ordem de escrita e leitura tem peso até hoje na educação e história cultural da China, igualmente na intepretação e conhecimento da escrita antiga (古文 - guwen). Tal ordem principalmente se baseia da seguinte

\footnotetext{
${ }^{30}$ Pedra preciosa que na China antiga carrega grande valor e grande significado, uma vez que em sua mitologia uma caracterização do palácio que os principais deuses ocuparia seria referente a este tipo de material, o chamado "Palácio de Jade".
} 


\section{traduções}

\section{O Selo de Jade Imperial Taiping e o Reino do Filho Chinês de Deus}

forma: de cima para baixo, do meio para os lados e da esquerda para a direita poderse-ia ler: “太平玉尔/Taiping Yuxi; 天父上帝/Tianfu Shangdi; 恩和輯睦/Enhe Jimu; 天王洪 日/Tianwang Hongri; 天兄基督/Tianxiong Jidu; 救世幼主/Jiushi Youzhu; 主王與篤 /Zhuwang Yudu; 八位萬嵅/Bawei Wansui; 真王貴福 /Zhengwang Guifu; 永定乾坤 /Yondding Qiankun; 永锡天祿/Yongxi Tianlu."

A segunda maneira é ler primeiro as partes que contenham: “天父Tianfu; 天兄 Tianxiong; 天王Tianwang" e depois a frase restante, que está na parte superior do selo: “恩和輯睦/Enhe Jimu” Em seguida, lê-se a segunda parte, mais a baixo, contendo as oito "frases" na vertical, seguindo ainda a ordem de dentro para fora e da esquerda para a direita (LUO (罗), Suizu (隨祖). 1981, p.30).

Tal forma também traz características importantes, uma vez que divide o selo em duas partes, a primeira sendo principalmente uma espécie de "classificação do selo", e a segunda que traz o seu "conteúdo" propriamente dito. Por outro lado, também exalta as três figuras mais importantes dentro da teologia cristã dos Taiping, uma vez que Deus (天父Tianfu), Jesus (天兄Tianxiong) e Hong Xiuquan (天王Tianwang) são "anunciados" primeiro, podendo ser uma forma respeitosa de representa-los ou por homenageá-los. Por fim, o selo seria lido desta maneira: 太平玉玺/Taiping Yuxi; 天 父上帝/Tianfu Shangdi; 天兄基督/Tianxiong Jidu; 天王洪日/Tianwang Hongri; 恩和輯睦 /Enhe Jimu; 主王與篤/Zhuwang Yudu; 救世幼主/Jiushi Youzhu; 真王貴福 /Zhengwang Guifu; 八位萬嵅/Bawei Wansui; 永锡天祿/Yongxi Tianlu; 永定乾坤/Yondding Qiankun

Há um consenso entre os estudiosos da Rebelião Taiping nos quais definem um terceiro modo de leitura do selo, muito divergente dos anteriores. Primeiramente, é necessário explicar que Hong Xiuquan acreditava que, no céu, Jesus Cristo certamente estaria sentado ao lado direito de Deus, e como Hong identificava que Jesus Cristo era 


\section{traduções}

Victor Artuza

seu irmão mais velho, ele próprio deveria estar ao lado direito de Jesus Cristo. Neste sentido, dever-se-ia ler primeiramente: “天父上帝/Tianfu Shangdi; 天兄基督/Tianxiong Jidu; 天王洪日/Tianwang Hongri", como a primeira parte, e logo em seguida, continuar lendo (seguindo a ordem já estabelecida por essa primeira parte) de dentro para fora, da esquerda para a direita (LUO (罗), Suizu (隨祖). 1981, p. 30). A leitura final seria: “太 平玉胥/Taiping Yuxi; 天父上帝/Tianfu Shangdi; 天兄基督/Tianxiong Jidu; 天王洪日 /Tianwang Hongri; 主王與篤/Zhuwang Yudu; 救世幼主/Jiushi Youzhu; 真王貴福 /Zhengwang Guifu; 八位萬嵗/Bawei Wansui; 永锡天祿/Yongxi Tianlu; 永定乾坤 Mondding Qiankun; 恩和輯睦/Enhe Jimu."

Se por um lado esta última leitura, além de ser a mais aceita entre os estudiosos da rebelião, apresenta-se de forma concreta, já que Hong demonstrava uma forte religiosidade e a simbologia para ele era muito importante, tanto porque quando se trata de religião a simbologia se faz de extrema importância, quanto para exaltar a legitimidade da rebelião. Por outro lado, não deve-se descartar às outras duas interpretações, já que dentro da sociedade chinesa, e como também da mentalidade da época, tais interpretações deveriam ser utilizadas, assim estas se tornariam plausíveis. Pessoas que não participassem ou os seguidores provavelmente liam (ou pelo menos visualizavam) o selo seguindo à primeira ou segunda interpretação, uma vez que não possuíam uma mentalidade como a de Hong, sendo que a maior parte dos seguidores (advindos das camadas mais simples) não deveriam possuir um nível tão elevado de estudo.

Assim apresenta-se certa pluralidade de modos de leitura, o que consequentemente traz duas escolhas para a interpretação, uma envolvente e outra excludente. Logo, tais leituras poderiam ser opostas, ou seja, seus sentidos sendo excludentes; ou 


\section{traduções}

\section{O Selo de Jade Imperial Taiping e o Reino do Filho Chinês de Deus}

pelo contrário, tais leituras incorporam-se, adicionando-se mutualmente novos sentidos e significados? Tal questão é passível de discussão e coloca-se aqui com a função de problematizar tal questão.

Deve atentar-se para o fato que em todas as leituras “太平玉玺/Taiping Yuxi" é sempre lido primeiro, já que é o nome do selo. Assim, pode-se ler esta frase como sendo: "Selo de Jade Imperial Taiping", tendo como função nomear o selo.

“天父上帝/Tianfu Shangdi" é traduzido como "Deus o Pai" que se refere ao deus cristão, em que Hong desejava aqui demonstrar a forte relação que tinha com ele, ao se estabelecer legitimamente como “Rei Celestial"; “天兄基督/Tianxiong Jidu” traduz-se: "Irmão Jesus" em que demonstrava que Jesus Cristo era o irmão mais velho de Hong. Logo em seguida, “天王洪日/Tianwang Hongri", lê-se: "Rei Celestial, Hong", onde "Rei Celestial" era o título usado pelo próprio Hong Xiuquan, dada à ele pelo próprio "Pai" (detido através dos sonhos que tivera com este), estabelecendo-o como governante do Reino Celestial Taiping.

“主王與篤/Zhuwang Yudu” tem o sentido de: “Governante fiel ao povo", aqui, o governante, representado por Hong, é tido como sendo fidedigno, uma vez que se faz fiel ao seu povo e à manutenção da ordem Taiping, respeitando as vontades divinas; já “救世幼主/Jiushi Youzhu” como: "Jovem Regente, Salvador" indicando que o primogênito de Hong, Guifu, traria a Salvação do mundo; “真王貴福 /Zhengwang Guifu;" seria: "Guifu, futuro rei" designando que Guifu, era o verdadeiro e único herdeiro ao trono.

Na área existe certa polêmica quanto à tradução que carrega: “八位萬嵅/Bawei Wansui", já que há duas maneiras controversas de se traduzi-las, primeiramente pode se revelar como: "Os Oito Poderes", estes eram oito entidades de grande importância 


\section{traduções}

Victor Artuza

para a rebelião, estas eram: Deus; Jesus Cristo; o próprio Hong; seu primogênito, Guifu; o seu terceiro e o seu quarto filhos; e dois importantes líderes: Yang Xiuqing, Líder do Leste e Shi Dakai, o Líder do Oeste (LUO (罗), Suizu (隨祖). 1981, p. 31).

A segunda tradução, que é totalmente oposta a primeira, trazendo o seguinte sentido: “Vida longa à Hong”, em que Wansui (萬嵅) ${ }^{31}$ seria um título que poderia ser usado somente pelo imperador, enquanto os reis só poderiam utilizar Qiansui (千 岁 ${ }^{32}$, neste sentido, o único que poderia utilizar o título Wansui (萬嵗) era Hong. Isto também baseia-se na caracterização que os radicais do nome de Hong (洪): “シ , [u11] , 八" estão fortemente presentes em um documento do Reino Celestial Taiping, o Chao Tianchao Zhutu (朝天朝主圖) ${ }^{33}$, estes radicais representariam seu nome, formando assim a seguinte frase: “洪秀全正位萬嵅” (Hong Xiuquan Zhengwei Wansui), que significaria que Hong ostenta o lugar de Wansui, ou seja, imperador (LUO (罗), Suizu (隨祖). 1981, p. 31).

Ambas as formas de se ler o selo - que incidem diretamente na tradução apresentam-se de forma plausível uma vez que ambos os sentidos são validos, e se analisados do ponto de vista da rebelião, também concretamente podem se verificar, deixando assim uma dúvida, mas também uma dupla, talvez ambígua leitura. Uma das hipóteses que pode-se ter é o segundo sentido como determinante do empoderamento sobre a figura do Rei Celestial, que talvez somente após a rivalidade criada dentro do Reino Celestial Taiping a interpretação seria adotada para definir absolutamente seu lugar, "rebaixando" ou até "retirando" o papel dos outros líderes Taiping para com a representatividade do movimento. No entanto, a primeira interpretação

\footnotetext{
${ }^{31} \mathrm{Na}$ tradução literal significa 10 mil anos.

${ }^{32} \mathrm{Na}$ tradução literal significa 1 mil anos.

${ }^{33}$ Um sistema de terras agrícolas que tinha por base uma grande reforma agrária.
} 


\section{traduções}

\section{O Selo de Jade Imperial Taiping e o Reino do Filho Chinês de Deus}

seria válida para ordenar o movimento, erigindo e estabelecendo sua liderança, como também a cadeia de comando.

“永锡天祿/Yongxi Tianlu” significaria: “Sempre ofertar bênçãos", trazendo o sentido em que Hong estaria sempre abençoando o Reino Celestial Taiping, já que era irmão de Jesus, poderia dar benção divina ao reino; “永定乾坤 /Yondding Qiankun” estabelece: "Ordem Eterna entre o Céu e a Terra", neste sentido, o reino e principalmente Hong Xiuquan trariam uma ordem infindável para o mundo, o qual seria representado pelo "o Céu e a Terra”, segundo a tradição cristã. “恩和輯㓐/Enhe Jimu” é traduzido como: "Gratidão, Harmonia e Paz", já que deveria se ter gratidão a Deus, preservar a harmonia e a paz entre as pessoas, porquanto que todos são iguais perante Deus.

A partir deste ponto, feitas as traduções, pode-se agora iniciar-se a análise mais detalhada do selo, definindo a rebelião a partir do mesmo, como também confrontando as informações extraídas dele e outras obtidas a partir de outras fontes. Desse modo, as informações contidas no selo podem tanto adicionar, aprofundar ou até trazer novas percepções, contrastando ou convergindo com as informações obtidas através destas outras fontes, como por exemplo dos documentos oficiais (tais como cartas, decretos, entre outros).

Logo, um ponto a ser analisado seria concernente ao conhecimento que se tinha da religião cristã, já que Hong teve somente acesso aos tratados de Liang Afa e mais tardiamente à Biblia cristã, mas notadamente há um certo sincretismo, já que as bases do cristianismo Taiping se dão em uma junção de entidades cristãs com entidades chinesas, sejam elas advindas do taoísmo, budismo, etc. Outra questão seria que mais tardiamente, Hong, acreditando ser irmão mais novo de Jesus Cristo, tem 


\section{traduções}

Victor Artuza

uma percepção diferente quando mais tarde consegue acesso a outros textos sagrados, já que no final de sua vida passou a maior parte do tempo confinado em seu palácio modificando as traduções da Bíblia com o objetivo de que sua figura, como irmão de Jesus, fizesse-se presente dentro dos textos sagrados.

Neste sentido, inicialmente o uso dos tratados o fazem delinear as bases teológicas do cristianismo Taiping, o qual posteriormente, com seu extremo fundamentalismo religioso - uma vez que sua fé já estava formada - acreditava na teologia Taiping, ignorando ou não aceitando que novas informações sobre o cristianismo fossem admitidas, ou que a teologia Taiping fosse revista. Isto estava aliado à questão que obtivera contato direto com Deus (uma vez que nos sonhos os quais tivera com esse, quando estava doente) e o mesmo o ensinara o que seria o verdadeiro cristianismo, propagado pelos Taiping.

Um segundo ponto é a posição que Hong detinha, já que o mesmo era a centralização do poder, mas também de toda a simbologia e teologia cristã dentro da Rebelião Taiping, sendo interessante de ser analisada. Talvez esta caracterização do "Rei Celestial" - que pode ser tida através das interpretações aqui propostas para o selo - em que este era o líder supremo, sempre deveria estar acima dos outros líderes do movimento. Por este motivo, as traduções que visam o sentido de indicar uma valorização da figura do "Rei Celestial" foram escolhidas. Um exemplo deste choque entre Hong e outra liderança pode ser exemplificado quando do aumento da crença em que Yang seria a encarnação do Espírito Santo. Uma tentativa de oposição a isso seria a de reafirma-se como líder, apresentando que seu primogênito, Guifu, seria o verdadeiro e único herdeiro ao trono, o que assim pode-se colocar em confronto com uma das interpretações de “八位萬嵗”, que exaltaria as imagens dos reis da rebelião (o 


\section{traduções}

\section{O Selo de Jade Imperial Taiping e o Reino do Filho Chinês de Deus}

que incluiria Yang Xiuqing), porém, por outro lado, isto poderia representar a reafirmação da posição de cada um ao seu devido posto.

A determinação e o fervor religioso são facilmente observados no selo, além de ser um modo de legitimar tanto a rebelião quanto ao próprio Hong, também é possível perceber um modo de se impor o forte regimento de condutas radicais à população, pela valorização destas, frente à Deus, já que era este, que por meio de Hong, manifestava suas vontades. Deste modo, a simbologia e a ideologia por traz da Rebelião Taiping podem ser consideradas e melhor entendidas.

Assim, o Selo de Jade Imperial Taiping serve como um documento, não só que demonstra a complexidade e o modo como se organizou a Rebelião Taiping, mas como também para que se possa entender mais profundamente sua ideologia, sua mentalidade, quais eram os objetivos da rebelião e principalmente de Hong Xiuquan, o qual através do selo pode ser tido como figura principal do movimento (porém, não somente através deste, já que é a vida de Hong que influencia à organização de tal movimento). E como visto acima, o selo carrega importantes informações, essenciais para uma compreensão melhor.

Portanto, a Rebelião Taiping ocupou uma posição de importância na história da Dinastia Qing, seja por suas dimensões ou por suas consequências, ou por refletir e influenciar nas fraquezas do poder manchu, que consequentemente iriam abalar as bases chinesas, pondo um fim não só à Dinastia Qing, como também no período dinástico.

Logo, as influencias sobre a História da China são exorbitantes, contendo um significado muito fundamental na formação da China contemporânea, pois analisando tal movimento, pode-se atentar para muitas características desse período. 


\section{traduções}

Victor Artuza

Por fim, a tentativa aqui de se analisar o selo, na pretensão de encaixá-lo na posição que continha em seu devido contexto, foi explanada, resultando em um conhecimento melhor sobre a história da China, para se compreender a história de um país e uma cultura tão distantes da cultura brasileira. Espera-se assim que este artigo seja um incentivo à academia brasileira para se aventurar aos estudos, tão pouco realizados no país, da dispare e rica história da China.

\section{Referências Bibliográficas}

FAIRBANK, John K.; GOLDMAN, Merle. China: A New History. Enlarged Edition. London: The Belknap Press of Havard University Press. 2001.

GERNET, Jacques. O Mundo Chinês: Um civilização e uma história. Tradução de José Manuel da Silva Lopes. Edição Cosmos. Lisboa - Rio de Janeiro. 1974.

HISTÓRIA Geral da China (中国通史). Equipe de Direção: Li Dongyan(李东艳), Liyajun(黎亚军), Teng Zhongbin(滕忠彬), Chen Shiping(沈世平), Wei Shengze(魏圣泽), Yan Fei(闻非), Zhong Yixuan(锤艺萱), Tian Bo(田波), Song Chunlai(宋春来), Li Qianru(李 倩茹), Jiang Junjie(蒋俊杰), Yang Jing(杨景), Liu Linghao(刘领浩), Marc C. Pingry, Sigal Bujman, René Seegers. Produção: Zhao Li (赵力), Liu Yutao (刘羽涛). China: Produtora Dianying Pingdao Jiemu Zhongxin(电影频道节目中心), 2016. 1 Vídeo(45min.). Disponível em:https://www.youtube.com/watch?v=q78LNmCNQkc\&index=97\&list=PLinivvyLwn6 b14N30QhqD5jpvcvAWkOzY. Último acesso em 04 de setembro de 2019.

LUO (罗), Suizu (隨祖). Taiping Tianguo de Liangfang Yuxi(太平天国的两方玉玺) Pequim(北京), Zijincheng (紫禁城), 1981. 


\section{traduções}

O Selo de Jade Imperial Taiping e o Reino do Filho Chinês de Deus

SPENCE, Jonathan D. Em busca da China moderna: quatro séculos de história. São Paulo: Companhia das Letras, 1996a.

. God's Chinese Son: The Taiping Heavenly Kingdom of Hong

Xiuquan. New York: W.W. Norton \& Company, 1996b.

\section{Imagens}

Imagem 1: LUO (罗), Suizu (隨祖). Taiping Tianguo de Liangfang Yuxi(太平天国的两方玉 玺) Pequim(北京), Zijincheng (紫禁城), 1981. 